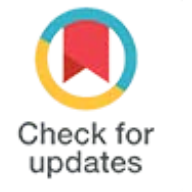

DOI: $10.29252 / \mathrm{ijcp}-25263$

\section{Lipid Profile Parameters and Coronary Artery Disease in Young Patients Undergoing Diagnostic Angiography}

\author{
Ashwal A Jayaram ${ }^{1,}{ }^{*}$, Krishnanada Nayak ${ }^{2}$, Sudhakar M Rao ${ }^{1}$, \\ Jyothi Samanth ${ }^{2}$, Sneha T Kvellur ${ }^{2}$, Adamya Saleel ${ }^{2}$, Yasir \\ Almalki $^{2}$, Nirlip Gajiwala ${ }^{3}$ \\ ${ }^{1}$ Department of Cardiology, Kasturba Medical College, Manipal Academy of \\ Higher Education, Manipal, India \\ ${ }^{2}$ Department of Cardiovascular Technology, School of Allied Health Science \\ (SOAHS), Manipal University, Manipal, India \\ ${ }^{3}$ Sahajanand Medical Technologies Pvt. Ltd., Surat, India \\ ${ }^{*}$ Corresponding author: Ashwal A J, Department of Cardiology, Kasturba Medical \\ College, Manipal Academy of Higher Education, Manipal, India. Tel: +94- \\ 81506690,E-mail:dr.ashwal@gmail.com
}

\begin{abstract}
Introduction: It is vital to understand the association between lipid profile and the severity of coronary artery disease $(\mathrm{CAD})$ in young patients with suspected $\mathrm{CAD}$. The clinical presentation, lipid profile and severity of CAD may differ in patients who develop $\mathrm{CAD}$ at young age and those at older age. Friesinger (FR) index is an important tool to assess the extent and severity of coronary artery lesions.

Methods: This study was a single center retrospective study involving patients below 40 years who underwent diagnostic coronary angiography. Demographic variables, lipid profile and FR index were estimated. Patients were divided into four groups based on the FR index scores of $0,1-4,5-10$ and 11-15, respectively.

Results: A total of 158 patients (Mean \pm SD of age; $35.65 \pm 3.81$ years) were included in the study. Among demographic variables, gender $(\mathrm{P}=0.03)$ and body mass index (BMI) $(\mathrm{P}<0.001)$ were found to be associated with FR index. In addition, total cholesterol $(\mathrm{P}<0.001)$, low density cholesterol $(\mathrm{LDL})$ cholesterol $(\mathrm{P}<0.001)$, nonhigh density cholesterol (non-HDL) $(\mathrm{P}<0.001)$ and ratio of triglycerides $(\mathrm{TG}) /$ nonHDL cholesterol $(\mathrm{P}=0.004)$ showed significant differences between the FR groups. Logistic regression analysis showed that only diabetes $(\mathrm{P}=0.02)$ and $\mathrm{BMI}(\mathrm{P}=0.004)$ were significant predictors of the extent and severity of coronary artery lesions in terms of FR index.

Conclusions: A strong direct relationship was observed between total cholesterol, LDL and non HDL cholesterol while a negative correlation with the TG/non HDL ratio. Diabetes and BMI also play a very significant role.
\end{abstract}

\section{INTRODUCTION}

Coronary artery disease $(\mathrm{CAD})$ is one of the leading causes of morbidity and mortality. It accounts for around 12 million deaths worldwide annually [1]. In particular, it is a major clinical concern in South Asia, as more than a half of the worldwide CAD risk burden is estimated to be borne by Indian subcontinent [2]. Reports have also suggested that the risk of developing $\mathrm{CAD}$ in Asian Indians is 3-4 times higher than that in white Americans, 6 times higher than that in Chinese, and 20 times higher than that in Japanese [3]. In addition to higher rate, it is also reported that Indian individuals may develop $\mathrm{CAD}$ at a very early age [4]. Onset of CAD before 40 years of age is considered as premature $\mathrm{CAD}[5,6]$. Although most studies reported that only about $3 \%$ of all CAD cases occur below 40 years of age, it should be considered as the 'tip of the 
iceberg' as young, asymptomatic patients usually do not undergo medical investigations $[7,8]$. It has been noted that more than a half of death related to cardiovascular disease occurs in patients below the age of 50 years and one-fourth of patients with acute myocardial infarction are reported in patients under the age of 40 years in India [6]. It has also been noted that the clinical presentation, cardiovascular risk factors, lipid profile and severity of $\mathrm{CAD}$ may differ in patients who develop $\mathrm{CAD}$ at young age and those who develop $\mathrm{CAD}$ at an older age [6, 9$11]$.

In this this milieu, it is vital to understand the association between lipid levels and the extent or severity of coronary lesions in young patients with coronary artery disease. Friesinger (FR) index is an important tool to assess the extent and severity of coronary artery lesions [12]. A significant association between the FR index and lipid levels has been observed previously [13, 14]. However, such investigations in specifically young Indian population are not available in the literature. Hence, we conducted the present study to evaluate the association between certain lipid parameters and the extent of $\mathrm{CAD}$, in terms of FR index, in young patients undergoing diagnostic coronary angiography. This will help us in focusing on early detection and treatment of abnormal lipid levels along with lifestyle changes in predisposed individuals.

\section{MATERIALS AND METHODS}

\section{Study Design}

This study was a single center retrospective study conducted at a tertiary care center in South India. All consecutive patients presenting with myocardial infarction (MI) or unstable angina (UA) below 40 years who underwent coronary angiography for diagnostic purposes at our hospital from 2009 to 2017 entered the study. However, patients with previous myocardial infarction, congenital heart disease, coronary artery anomaly, obstructive pulmonary illness and reported use of cholesterol-lowering drugs, history of percutaneous angioplasty and history of cardiac surgery were excluded. The protocol of the study was approved by the Institutional Ethics Committee and the study was conducted in accordance with the ethical standards of Good Clinical Practice and the Helsinki Declaration.

\section{Data Collection}

Data was obtained retrospectively from the review of medical records, including coronary angiography reports, at the hospital. For each patient, demographic data was collected including age, sex, height, weight, systemic arterial hypertension, diabetes mellitus, smoking habits and alcoholism. Body Mass Index (BMI) was calculated by weight divided by height squared. Blood pressure (BP) was recorded in the sitting position in the right arm with a mercury sphygmomanometer. Two readings were taken by a trained physician 5 minutes apart and the mean of the two was noted as the BP. Systemic arterial hypertension was defined as systolic blood pressure $>140 \mathrm{mmHg}$ or diastolic blood pressure $>90 \mathrm{mmHg}$ or by previous diagnosis or prior use of anti-hypertensive drugs [6]. Diabetes mellitus was defined by $\geq 126 \mathrm{mg} / \mathrm{dL}$ fasting blood sugar along with glycated hemoglobin (HbAlc) levels $>6.5 \%$, or previous diagnosis or prior use of hypoglycemic drugs [6]. Patients were labelled as smokers or alcoholic if they gave history of its consumption within the last one year.

To analyze the lipid profile, a $5 \mathrm{~mL}$ venous blood sample was collected from each patient. Subsequently, total cholesterol (TC), triglycerides, high-density lipoprotein (HDL) cholesterol, low-density lipoprotein (LDL) cholesterol, very-low-density lipoprotein (VLDL) cholesterol and non-HDL cholesterol levels were calculated using standard methods. Lipid ratios of triglycerides to HDL cholesterol and triglycerides to non-HDL cholesterol as well as total cholesterol to HDL were also calculated. Patients with abnormal lipid levels were identified by cutoff points of $>200 \mathrm{mg} / \mathrm{dL}$ for total cholesterol, $>150 \mathrm{mg} / \mathrm{dL}$ for triglycerides, $>130 \mathrm{mg} / \mathrm{dL}$ for LDL cholesterol, $\leq 40 \mathrm{mg} / \mathrm{dL}$ for HDL cholesterol, $\leq 5$ for total cholesterol/HDL ratio, $>4$ for triglycerides/HDL cholesterol ratio and $>0.9$ for triglycerides/ non-HDL cholesterol ratio [13].

For all patients, coronary angiography was performed either by radial or trans-femoral route by experienced cardiologists to detect significant CAD. Here, significant CAD was defined as $\geq 50 \%$ stenosis in the left main coronary artery, $\geq 70 \%$ stenosis in any other coronary artery, or both [15]. Based on the involvement of none, one, two, three vessels, patients were divided into those with normal coronaries, single vessel disease, double vessel disease and triple vessel disease, respectively. Additionally, the Friesinger index (FR) was used to assess the coronary artery disease burden. Each one of the three main coronary arteries was scored separately from zero to five. The scores were 0 for normal or no angiographic abnormality, 1 for luminal narrowing of less than $29 \%, 2$ for localized luminal narrowing of 30 $68 \%$, 3 for multiple luminal narrowing of $30-68 \%$, 4 for luminal narrowing of $69-100 \%$ without total occlusion of proximal segment and 5 for total obstruction of a proximal segment [14]. Finally total score comprising sum of the scores of the three coronary arteries for an individual were calculated. Accordingly, patients were classified into FR index groups comprising (a) patients with 0 score of FR index, (b) 1-4 score of FR index, (c) 5-10 score of FR index and (d) those with 11-15 FR index score.

\section{Statistical Analysis}

Continuous variables were presented as mean and standard deviation while categorical variables presented as frequency and percentage. The Analysis of Variance (ANOVA) test was used to assess the significant differences between FR index groups for continuous 
demographic variables (e.g. age, height, weight, BMI) and lipid profile (e.g. total cholesterol, triglycerides, HDL cholesterol, LDL cholesterol, VLDL cholesterol, non-HDL cholesterol, total cholesterol/HDL cholesterol, triglycerides/HDL cholesterol and triglycerides/non-HDL cholesterol). Similarly, Pearson Chi-square test was used to assess the significant differences between FR index groups for categorical demographic variables (e.g. age groups, gender, BMI groups, hypertension, diabetes, smoking, alcohol) and for CAD severity (e.g. normal coronaries, single vessel disease, double vessel disease and triple vessel disease). Spearman's rho correlation test was used to assess the correlation between FR index and various lipid profile components with an estimation of correlation coefficient (r). Subsequently, the association between the severity of FR index and frequencies of patients classified according to the cut-off levels for each lipid variable was assessed using Pearson Chi-square test. In addition, we dichotomized the scale of FR index into binary, FR $\geq 5$ as high coronary artery disease burden. binary logistic regression analysis with this cut-off was conducted to predict the extent and severity of coronary artery lesions, in terms of FR index, using lipid variables and demographic characteristics as predictors along with odds ratio and 95\% confidence interval for regression coefficient $(\mathrm{R})$. The Statistical Package for Social Sciences (SPSS for Windows version 20.0; Chicago, IL, USA) was used for statistical analysis. P value $<0.05$ was considered to indicate statistical significance.

\section{RESULTS}

\section{Baseline Demographics}

This study included a total of 158 patients aged less than 40 years who underwent diagnostic coronary angiography during the study period at our center. The baseline characteristics of these patients are given in Table 1. The mean age of study population was $35.65 \pm 3.81$ years. Of them, $129(81.6 \%)$ were males and 29 (18.4\%) females. Cardiovascular risk factors such as hypertension, diabetes, smoking habits and alcoholism were present in 41 (25.94\%), 52 (32.91\%), 37 (23.4\%) and $7(4.4 \%)$ patients, respectively.

Lipid profile analysis revealed that the mean total cholesterol level was $168.05 \pm 52.03 \mathrm{mg} / \mathrm{dL}$, mean triglycerides level $152.44 \pm 101.79 \mathrm{mg} / \mathrm{dL}$, mean HDL cholesterol level $38.72 \pm 12.76 \mathrm{mg} / \mathrm{dL}$, mean $\mathrm{LDL}$ cholesterol level $100.53 \pm 44.07 \mathrm{mg} / \mathrm{dL}$, mean VLDL cholesterol level $30.22 \pm 0.37 \mathrm{mg} / \mathrm{dL}$, mean non-HDL cholesterol level $129.33 \pm 49.22 \mathrm{mg} / \mathrm{dL}$, mean ratio of total cholesterol to HDL $4.94 \pm 3.74$, mean ratio of triglycerides to HDL ratio $4.46 \pm 3.67$ and mean ratio of triglycerides to non-HDL $0.64 \pm 0.48$.

Angiographic analysis revealed that 61 (38.6\%), 68 (43.0\%), $23(14.6 \%)$ and $6(3.8 \%)$ patients had normal coronaries, single vessel disease, double vessel disease and triple vessel disease, respectively. Further, the mean
FR index was $3.77 \pm 4.14$. Of them, $61(38.6 \%)$ patients had score 0 of FR index, $41(26.0 \%)$ score $1-4$ of FR index, 41 (26.0\%) score 5-10 of FR index and 15 (9.4\%) score $11-15$ of FR index.

\begin{tabular}{|c|c|}
\hline Variable, $n=158$ & \\
\hline Age (years) & $35.65 \pm 3.81$ \\
\hline Males & $129(81.6)$ \\
\hline Females & $29(18.4)$ \\
\hline Body mass index $(\mathrm{kg} / \mathrm{m} 2)$ & $24.66 \pm 3.18$ \\
\hline Smoking & $37(23.4)$ \\
\hline Hypertension & $41(25.94)$ \\
\hline Alcohol & $7(4.4)$ \\
\hline Diabetes & $52(32.91)$ \\
\hline \multicolumn{2}{|l|}{ Lipid Profile } \\
\hline Total cholesterol, mg/dL & $168.05 \pm 51.03$ \\
\hline Triglycerides, mg/dL & $152.44 \pm 101.79$ \\
\hline HDL cholesterol, mg/dL & $38.72 \pm 12.76$ \\
\hline LDL cholesterol, mg/dL & $100.53 \pm 44.07$ \\
\hline VLDL cholesterol, mg/dL & $30.22 \pm 20.37$ \\
\hline Non-HDL cholesterol, mg/dL & $129.33 \pm 49.22$ \\
\hline Total Cholesterol/HDL & $4.94 \pm 3.74$ \\
\hline Triglycerides/HDL cholesterol & $4.46 \pm 3.67$ \\
\hline $\begin{array}{l}\text { Triglycerides/non-HDL } \\
\text { cholesterol }\end{array}$ & $0.64 \pm 0.48$ \\
\hline \multicolumn{2}{|l|}{ Angiographic Diagnosis } \\
\hline Normal Coronaries & $61(38.6)$ \\
\hline Single vessel disease & $68(43.0)$ \\
\hline Double vessel disease & $23(14.6)$ \\
\hline Triple vessel disease & $6(3.8)$ \\
\hline Freisinger Index & $3.77 \pm 4.14$ \\
\hline $0, \mathrm{n}(\%)$ & $61(38.6)$ \\
\hline $1-4, \mathrm{n}(\%)$ & $41(26.0)$ \\
\hline $5-10, \mathrm{n}(\%)$ & $41(26.0)$ \\
\hline $11-15, \mathrm{n}(\%)$ & $15(9.4)$ \\
\hline
\end{tabular}

Data in table are presented as No. (\%) or Mean \pm SD HDL: high density cholesterol; LDL: low density cholesterol; VLDL: very low density cholesterol

\section{Demographic Profile vis-à-vis FR Index Groups}

The comparative analysis of demographic variables between FR index groups is given in Table 2. Severity of coronary artery disease showed a strong association with FR index $(\mathrm{P}<0.001)$. In addition, gender and BMI showed significant role in the FR index, with trends suggesting more predominance of males $(P=0.03)$ and increase in BMI $(\mathrm{P}<0.001)$ with increase in FR index.

\section{Lipid Profile vis-à-vis FR Index}

The comparative analysis of lipid profile between FR index groups is given in Table 3. Significant differences were observed between total cholesterol $(\mathrm{P}<0.001)$, LDL cholesterol $(\mathrm{P}<0.001)$, non-HDL cholesterol ( $\mathrm{P}$ $<0.001)$ and triglycerides/non-HDL cholesterol ( $\mathrm{P}=$ 0.004). Further, the analysis of correlation between FR index and various lipid profile components is given in Table 4. A significant positive correlation was observed between FR index and total cholesterol $(\mathrm{r}=0.189 ; \mathrm{P}=$ $0.018)$, LDL cholesterol $(\mathrm{r}=0.222$; $\mathrm{P}=0.005)$, nonHDL cholesterol $(\mathrm{r}=0.206 ; \mathrm{P}=0.009)$. Of note, a significant inverse correlation was observed between FR index and ratio of triglycerides to non-HDL cholesterol $(\mathrm{r}=-0.205 ; \mathrm{P}=0.010)$. Table 5 presents the 
comparative analysis of frequency of patients with abnormal lipid levels between FR index groups. With increase in FR index, there was a trend of increase in the frequency of patients with elevated total cholesterol levels $(\mathrm{P}=0.009)$ and elevated LDL cholesterol levels $(\mathrm{P}=0.029)$.

Logistic Regression of Demographic Profile and Lipid Profile vis-à-vis FR Index
The binary logistic regression analysis of lipid variables and demographic characteristics vis-à-vis FR index (FR $\geq 5$ as high coronary artery disease burden) is given in Table 6. Among all variable, only diabetes $(\mathrm{P}=0.023)$ and BMI $(P=0.004)$ were found to be significant predictors of the extent and severity of coronary artery lesions, in terms of FR index. Of note, gender and all lipid variables showed no statistical significance.

Table 2. Demographic Variables in Patients Based on Freisinger Index Classes

\begin{tabular}{|c|c|c|c|c|c|}
\hline \multirow[t]{2}{*}{ Variables } & \multicolumn{4}{|c|}{ Freisinger Index } & \multirow[t]{2}{*}{ P value } \\
\hline & $0(n=61)$ & $1-4(n=41)$ & $5-10(n=41)$ & $11-15(n=15)$ & \\
\hline Age (years) & $35.07 \pm 4.39$ & $35.51 \pm 3.82$ & $36.27 \pm 2.75$ & $36.73 \pm 3.61$ & 0.09 \\
\hline Range & & & & & 0.1 \\
\hline $20-30$ years $[\mathrm{N}=17]$ & $8(47)$ & $5(29.4)$ & $3(17.6)$ & $1(5.9)$ & \\
\hline $31-40$ years $[\mathrm{N}=141]$ & $53(37.6)$ & $36(25.5)$ & $38(26.9)$ & $14(9.9)$ & \\
\hline Sex & & & & & 0.03 \\
\hline Males $[\mathrm{n}=129]$ & $43(33.3)$ & $36(27.9)$ & $37(28.7)$ & $13(10)$ & \\
\hline Females $[\mathrm{N}=29]$ & $18(62)$ & $5(17.2)$ & $4(13.7)$ & $2(6.8)$ & \\
\hline Height (cm) & $164.25 \pm 7.32$ & $166.37 \pm 5.54$ & $166.83 \pm 4.84$ & $161.33 \pm 9.54$ & 0.1 \\
\hline Weight $(\mathrm{cm})$ & $64.21 \pm 10.72$ & $68.44 \pm 9.48$ & $70.15 \pm 8.86$ & $69.53 \pm 8.55$ & 0.04 \\
\hline BMI (kg/m2) & $23.66 \pm 3.13$ & $24.68 \pm 2.97$ & $25.31 \pm 3.13$ & $26.87 \pm 2.70$ & $<0.001$ \\
\hline BMI & & & & & $<0.001$ \\
\hline $\mathrm{BMI} \leq 25 \mathrm{~kg} / \mathrm{m} 2[\mathrm{~N}=101]$ & $50(49.5)$ & $25(24.7)$ & $21(20.8)$ & $5(4.9)$ & \\
\hline $\mathrm{BMI}>25 \mathrm{~kg} / \mathrm{m} 2[\mathrm{~N}=57]$ & $11(19.3)$ & $16(28)$ & $20(35.0)$ & $10(17.5)$ & \\
\hline Smoking $[N=37]$ & $9(24.3)$ & $12(32.4)$ & $12(32.4)$ & $4(10.8)$ & 0.06 \\
\hline Hypertension $[\mathrm{N}=41]$ & $17(41.4)$ & $11(26.8)$ & $9(21.9)$ & $4(9.7)$ & 0.3 \\
\hline Alcohol $[\mathbf{N}=7]$ & $1(14.4)$ & $3(42.8)$ & $3(42.8)$ & 0 & 0.3 \\
\hline Diabetes $[\mathrm{n}=52]$ & $18(34.6)$ & $10(19.2)$ & $18(34.6)$ & $6(11.54)$ & 0.08 \\
\hline Normal coronaries $[N=61]$ & $61(100)$ & 0 & 0 & 0 & $<0.001$ \\
\hline Single vessel disease $[N=68]$ & 0 & $37(54.4)$ & $28(41.2)$ & $3(4.4)$ & \\
\hline Double vessel disease $[\mathrm{N}=23]$ & 0 & $4(17.4)$ & $11(47.8)$ & $8(34.7)$ & \\
\hline Triple vessel disease $[\mathrm{N}=6]$ & 0 & 0 & $2(33.3)$ & $4(66.7)$ & \\
\hline
\end{tabular}

Data in table are presented as No. (\%) or Mean \pm SD

BMI: Body mass index

Table 3. Lipid Levels in Patients Based on Freisinger Index Classes

\begin{tabular}{|c|c|c|c|c|c|}
\hline \multirow[t]{2}{*}{ Variables } & \multicolumn{4}{|c|}{ Freisinger Index } & \multirow[t]{2}{*}{ Pvalue } \\
\hline & $0(n=61)$ & $1-4(n=41)$ & $5-10(n=41)$ & $11-15(n=15)$ & \\
\hline Total cholesterol, mg/dL & $171.05 \pm 41.44$ & $149.78 \pm 49.81$ & $163.51 \pm 46.36$ & $218.20 \pm 69.65$ & $<0.001$ \\
\hline Triglycerides, mg/dL & $158.41 \pm 121.26$ & $153.61 \pm 103.05$ & $143.93 \pm 74.50$ & $148.20 \pm 81.15$ & 0.6 \\
\hline HDL cholesterol, mg/dL & $39.77 \pm 13.78$ & $39.15 \pm 13.36$ & $36.59 \pm 10.55$ & $39.13 \pm 12.83$ & 0.6 \\
\hline LDL cholesterol, mg/dL & $102.73 \pm 32.88$ & $81.63 \pm 41.60$ & $98.29 \pm 40.13$ & $149.33 \pm 63.05$ & $<0.001$ \\
\hline VLDL cholesterol, mg/dL & $31.574 \pm 24.33$ & $30.737 \pm 20.61$ & $28.493 \pm 14.95$ & $28.027 \pm 15.63$ & 0.4 \\
\hline Non-HDL cholesterol, mg/dL & $131.28 \pm 37.533$ & $110.63 \pm 50.43$ & $126.93 \pm 43.63$ & $179.07 \pm 68.75$ & $<0.001$ \\
\hline Total Cholesterol/HDL & $4.58 \pm 1.41$ & $5.38 \pm 6.88$ & $4.72 \pm 1.46$ & $5.84 \pm 2.20$ & 0.3 \\
\hline Triglycerides/HDL cholesterol & $4.628 \pm 4.60$ & $4.482 \pm 3.43$ & $4.319 \pm 2.61$ & $4.139 \pm 2.62$ & 0.6 \\
\hline Triglycerides/non-HDL cholesterol & $0.70 \pm 0.46$ & $0.71 \pm 0.46$ & $0.59 \pm 0.50$ & $0.33 \pm 0.49$ & 0.004 \\
\hline
\end{tabular}

Data in table are presented as Mean \pm SD

HDL: high density cholesterol; LDL: low density cholesterol; VLDL: very low density cholesterol

Table 4. Correlation between Freisinger Index and Lipid Variables

\begin{tabular}{lcc}
\hline Variables & \multicolumn{2}{c}{$\begin{array}{c}\text { Correlation with FR Index (Pearson's Correlation) } \\
\text { P value }\end{array}$} \\
\hline Total Cholesterol (mg/dL) & Correlation Coefficient & 0.01 \\
Triglyceride (mg/dL) & 0.189 & 0.6 \\
HDL $(\mathbf{m g} / \mathbf{d L})$ & -0.035 & 0.6 \\
\hline LDL $(\mathbf{m g} / \mathbf{d L})$ & -0.042 & 0.005 \\
VLDL (mg/dL) & 0.222 & 0.5 \\
Non HDL (mg/dL) & -0.050 & 0.009 \\
Total Cholesterol/HDL & 0.206 & 0.2 \\
Triglyceride/HDL & 0.087 & 0.6 \\
Triglyceride/Non HDL & -0.036 & 0.01 \\
\hline
\end{tabular}

Data in table are presented as No. (\%) or Mean \pm SD

HDL: high density cholesterol; LDL: low density cholesterol; VLDL: very low density cholesterol 
Table 5. Frequency of Patients According to the Cut-off Lipid Levels between Freisinger Index Groups

\begin{tabular}{|c|c|c|c|c|c|}
\hline \multirow[t]{2}{*}{ Cut-off level } & \multicolumn{4}{|c|}{ Freisinger Index } & \multirow[t]{2}{*}{ Pvalue } \\
\hline & $0(n=61)$ & $1-4(n=41)$ & $5-10(n=41)$ & $11-15(n=15)$ & \\
\hline TC & & & & & $0.009^{*}$ \\
\hline$\leq 200 \mathrm{mg} / \mathrm{dL}[\mathrm{N}=120]$ & $49(40.8)$ & $34(28.3)$ & $31(25.8)$ & $6(5)$ & \\
\hline$>200 \mathrm{mg} / \mathrm{dL}[\mathrm{N}=38]$ & $12(31.6)$ & $7(18.4)$ & $10(26.3)$ & $9(23.7)$ & \\
\hline HDL & & & & & 0.3 \\
\hline$\leq 40 \mathrm{mg} / \mathrm{dL}[\mathrm{N}=103]$ & $39(37.8)$ & $27(26.2)$ & $26(25.2)$ & $11(10.6)$ & \\
\hline$>40 \mathrm{mg} / \mathrm{dL}[\mathrm{N}=55]$ & $22(40)$ & $14(25.5)$ & $15(27.2)$ & $4(7.2)$ & \\
\hline LDL & & & & & $0.02 *$ \\
\hline$\leq 130 \mathrm{mg} / \mathrm{dL}[\mathrm{N}=122]$ & $48(39.3)$ & $36(29.5)$ & $31(25.4)$ & $7(5.7)$ & \\
\hline$>130 \mathrm{mg} / \mathrm{dL}[\mathrm{N}=36]$ & $13(36.1)$ & $5(13.8)$ & $10(27.7)$ & $8(22.2)$ & \\
\hline TG & & & & & 0.5 \\
\hline$\leq 150 \mathrm{mg} / \mathrm{dL}[\mathrm{N}=99]$ & $39(39.4)$ & $24(24.2)$ & $27(27.3)$ & $9(9.1)$ & \\
\hline$>150 \mathrm{mg} / \mathrm{dL}[\mathrm{N}=59]$ & $22(37.3)$ & $17(28.8)$ & $14(23.7)$ & $6(10.1)$ & \\
\hline Non HDL & & & & & 0.1 \\
\hline$\leq 160 \mathrm{mg} / \mathrm{dL}[\mathrm{N}=117]$ & $44(37.6)$ & $35(29.9)$ & $31(26.5)$ & $7(5.9)$ & \\
\hline$>160 \mathrm{mg} / \mathrm{dL}[\mathrm{N}=41]$ & $17(41.5)$ & $6(14.6)$ & $10(24.4)$ & $8(19.5)$ & \\
\hline TC/HDL & & & & & 0.07 \\
\hline$\leq 5[\mathrm{~N}=102]$ & $41(40.2)$ & $30(29.4)$ & $24(23.5)$ & $7(6.8)$ & \\
\hline$>5[\mathrm{~N}=56]$ & $20(35.7)$ & $11(19.6)$ & $17(30.3)$ & $8(14.2)$ & \\
\hline TG/HDL & & & & & 0.3 \\
\hline$\leq 4[\mathrm{~N}=91]$ & $38(41.7)$ & $22(24.4)$ & $22(24.4)$ & $9(10)$ & \\
\hline$>4[\mathrm{~N}=67]$ & $23(34.3)$ & $19(28.4)$ & $19(28.4)$ & $6(8.9)$ & \\
\hline TG/Non HDL & & & & & $0.006^{*}$ \\
\hline$\leq 0.9[\mathrm{~N}=57]$ & $18(31.6)$ & $12(21)$ & $17(29.8)$ & $10(17.5)$ & \\
\hline$>0.9[\mathrm{~N}=101]$ & $43(42.5)$ & $29(28.7)$ & $24(23.8)$ & $5(4.9)$ & \\
\hline
\end{tabular}

Data in table are presented as No. (\%)

TC: Total Cholesterol; HDL: high density cholesterol; LDL: low density cholesterol; TG: Triglyceride

Table 6. Logistic Regression Analysis for Demographic and Lipid Variables vs. the Friesinger Index

\begin{tabular}{lccccc}
\hline Variable & Regression Coefficient & Odds ratio & \multicolumn{1}{c}{ 95 \% Confidence Interval } & P value \\
\hline Diabetes & -0.891 & 0.410 & 0.191 & 0.884 & 0.02 \\
BMI & 0.175 & 1.191 & 1.056 & 1.344 \\
Sex & -0.020 & 0.345 & 0.118 & 1.012 \\
TC & 0.005 & 0.980 & 0.949 & 0.004 & 0.05 \\
LDL & -1.063 & 1.028 & 0.991 & 1.066 \\
HDL & 0.063 & 1.005 & 0.960 & 0.2 \\
TG/Non-HDL & 0.028 & 1.065 & 0.596 & 1.053 \\
\hline
\end{tabular}

BMI: body mass index; TC: Total Cholesterol; HDL: high density cholesterol; LDL: low density cholesterol; TG: Triglyceride

\section{DISCUSSION}

The present study compared the lipid profile and angiographic extent of coronary artery lesions in 158 young patients undergoing diagnostic coronary angiography. We observed significant $\mathrm{CAD}$ in $71.4 \%$ of patients. Among demographic variables, gender and BMI were found to be associated with FR index, which indicates the extent and severity of CAD. In addition, total cholesterol, LDL cholesterol and non-HDL cholesterol showed significant differences between FR groups. We believe that these findings may help in decision-making of management strategy in young patients with CAD.

According to the National Commission on Macroeconomics and health estimate, patients with $\mathrm{CAD}$ in India have increased from 29.8 to 61.5 million from 2004 to 2015 and the mortality rate has increased from 1.3 to 2.946 million [16]. Numerous studies have shown that high levels of LDL cholesterol are directly related to coronary artery disease $[17,18]$ and low level of HDL cholesterol has been considered as one of the strongest and most independent risk factors for the coronary artery disease $[19,20]$. It is also established that small increases in triglyceride levels may lead to rapid progression of coronary artery disease along with increased risk of new coronary artery lesions formation [21-23]. Further, several lipid ratios like ratio of triglycerides to HDL cholesterol has shown a very promising surrogate marker for the atherosclerosis [24]. However, previous studies have shown that most patients with acute ST segment elevation myocardial infarction and less than 40 years of age had low HDL levels, normal LDL levels, marginally elevated mean triglyceride levels and normal total cholesterol levels [11]. Conversely, very few studies have been performed to show a significant association between lipid levels and severity of coronary lesions, despite the association between lipid profile abnormality and coronary artery disease is very well known [25].

Earlier, Agarwal et al. evaluated the correlation between lipid levels and the extent or severity of coronary lesions in 566 patients (mean \pm SD of age; $56.17 \pm 9.99$ years) with suspected coronary artery disease using FR index (FR). The mean FR index was $5.40 \pm 3.78$. They demonstrated a significantly positive correlation between FR index and total cholesterol, triglycerides, VLDL cholesterol, non-HDL cholesterol, 
triglycerides/HDL cholesterol ratio and triglycerides/non-HDL cholesterol ratio. In addition, a negative correlation was observed between FR index and HDL cholesterol. Among demographic variables, age or gender did not alter the FR index severity but BMI, hypertension, diabetes and smoking showed significant association with FR index (13). Similarly, we divided our 158 young patients who aged $<40$ years into four groups based on FR index scores of $0,1-4,5-10$ and $11-15$ respectively. We observed that total cholesterol, LDL cholesterol, non-HDL cholesterol, triglycerides/non-HDL cholesterol ratio as well as BMI, weight and male gender had a significant correlation with severity of FR index in our patients. According to the cut-off lipid levels, total cholesterol $(>200 \mathrm{mg} / \mathrm{dl}$ ) and LDL cholesterol $(<130 \mathrm{mg} / \mathrm{dl})$ showed a direct association while triglyceride/non-HDL cholesterol (> $0.9)$ showed an inverse association with FR index. High levels of lipid profiles showed a direct impact on the severity of coronary artery disease. Higher BMI was also associated with higher FR index, which was also suggestive of increased BMI associated with $\mathrm{CAD}$ burden. Further, males with higher FR index showed higher prevalence of $\mathrm{CAD}$ compared to females. However, logistic regression analysis showed that only diabetes and BMI had strong association with the FR index. The main difference between our study and Agarwal et al. is that triglyceride/non-HDL cholesterol ratio had a contradictory correlation in both studies. Patients with dyslipidemia were excluded in the study. In another study, Luz et al. studied the association between lipid levels, specifically triglycerides/HDL cholesterol and the extent of coronary disease in 374 high-risk patients. They found that the association between the extent of coronary disease (dichotomized by a FR index of 5) and lipid levels (normal vs. abnormal) was statistically significant for triglycerides, HDL cholesterol and triglycerides/HDL cholesterol. However, the association was not significant between the extent of coronary disease and total cholesterol or LDL cholesterol [14]. According to a study by Flowers et al. triglycerides/HDL cholesterol ratio in Indian population was very useful in predicting clinical outcomes in apparently healthy people who had a risk of developing type 2 diabetes mellitus, cardiovascular disease along with metabolic syndrome [26].

Overall, we suggest that young patients may be predisposed at $\mathrm{CAD}$ and hence, emphasis should be given on diagnosis and management of dyslipidemia, which is a major modifiable risk factor for the primary and secondary prevention of coronary artery disease and subsequent cardiovascular events.

\section{Study Limitations}

We only considered lipid variables and did not take the current use of medication into account. The use of Angiotensin inhibitors or Angiotensin II receptor blockers may alter the association between lipid variables and FR index. Our study population included patients who underwent coronary angiography for diagnostic purposes and hence the findings might not be applicable to general population.

\section{CONCLUSIONS}

Our study showed a significant association between different lipid parameters and the coronary artery disease burden. A strong direct association was observed between total cholesterol, LDL and non HDL cholesterol while a negative correlation with TG/non HDL ratio. Diabetes and BMI also play a very significant role. However, our study clearly demonstrated that there was no statistically significant association between TG/HDL ratio and coronary artery disease burden.

\section{Financial Disclosure}

The authors report no financial relationships or conflicts of interest regarding the content herein.

\section{REFERENCES}

1. Sanchis-Gomar F, Perez-Quilis C, Leischik R, Lucia A. Epidemiology of coronary heart disease and acute coronary syndrome. Ann Transl Med. 2016;4(13):256. doi: 10.21037/atm.2016.06.33 pmid: 27500157

2. Yusuf S, Ounpuu S. Tackling the growing epidemic of cardiovascular disease in South Asia. J Am Coll Cardiol. 2001;38(3):688-9. doi: 10.1016/s0735-1097(01)01417-6 pmid: 11527618

3. Sharma M, Ganguly NK. Premature coronary artery disease in Indians and its associated risk factors. Vasc Health Risk Manag. 2005;1(3):217-25. pmid: 17319107

4. Chakraborty B, Zaman F, Sharma A. Combating coronary artery disease in South Asia-What is special. Bangladesh J Cardiol. 2009; 1(2):88-90.

5. Siddique MA, Shrestha MP, Salman M, Haque KS, Ahmed $\mathrm{MK}$, Sultan MAU, et al. Age-related differences of risk profile and angiographic findings in patients with coronary heart disease. Bangabandhu Sheikh Mujib Med Univ J. 2010;3(1):13-7. doi: 10.3329/bsmmuj.v3i1.5508

6. Prajapati J, Joshi H, Sahoo S, Virpariya K, Parmar M, Shah K. AGE-Related Differences of Novel Atherosclerotic Risk Factors and Angiographic Profile Among Gujarati Acute Coronary Syndrome Patients. J Clin Diagn Res. 2015;9(6):OC05-9. doi: 10.7860/JCDR/2015/11709.6000 pmid: 26266146

7. Gaziano TA, Bitton A, Anand S, Abrahams-Gessel S, Murphy A. Growing epidemic of coronary heart disease in low- and middle-income countries. Curr Probl Cardiol. 2010;35(2):72115. doi: 10.1016/j.cpcardiol.2009.10.002 pmid: 20109979

8. Deora S, Kumar T, Ramalingam R, Nanjappa Manjunath C. Demographic and angiographic profile in premature cases of acute coronary syndrome: analysis of 820 young patients from South India. Cardiovasc Diagn Ther. 2016;6(3):193-8. doi: 10.21037/cdt.2016.03.05 pmid: 27280082

9. Badran HM, Elnoamany MF, Khalil TS, Eldin MM. Agerelated alteration of risk profile, inflammatory response, and angiographic findings in patients with acute coronary syndrome. Clin Med Cardiol. 2009;3:15-28. doi: 10.4137/CMC.S2118 pmid: 20508763

10. Yildirim N, Arat N, Dogan MS, Sokmen Y, Ozcan F. Comparison of traditional risk factors, natural history and angiographic findings between coronary heart disease patients with age $<40$ and $>$ or $=40$ years old. Anadolu Kardiyol Derg. 2007;7(2):124-7. pmid: 17513205

11. Jayaram AA, Shah S. Risk factors, clinical features, angiographic characteristics and treatment outcomes of young myocardial 
infarction patients. J Indian Coll Cardio. 2015;5(3):203-8. doi: 10.1016/j.jicc.2015.05.002

12. Ringqvist I, Fisher LD, Mock M, Davis KB, Wedel H, Chaitman BR, et al. Prognostic value of angiographic indices of coronary artery disease from the Coronary Artery Surgery Study (CASS). J Clin Invest. 1983;71(6):1854-66. doi: 10.1172/jcil10941 pmid: 6863543

13. Agarwal D, Sinha RP, Jaiswal RM, Pursnani N, Gajiwala N, Thakkar A. Link between Friesinger Index and Lipid Profile in Patients Undergoing Diagnostic Coronary Angiography. International Journal of Clinical Medicine. 2015;06(08):53846. doi: $10.4236 /$ ijcm.2015.68072

14. da Luz PL, Favarato D, Faria-Neto JR, Jr., Lemos P, Chagas AC. High ratio of triglycerides to HDL-cholesterol predicts extensive coronary disease. Clinics (Sao Paulo). 2008;63(4):427-32. doi: 10.1590/s180759322008000400003 pmid: 18719750

15. Maddox TM, Stanislawski MA, Grunwald GK, Bradley SM, Ho PM, Tsai TT, et al. Nonobstructive coronary artery disease and risk of myocardial infarction. JAMA. 2014;312(17):1754-63. doi: 10.1001/jama.2014.14681 pmid: 25369489

16. Sriharibabu M. Changing trends in the prevalence of coronary heart disease. Indian Heart J. 2016;68(4):445-6. doi: 10.1016/j.ihj.2016.04.008 pmid: 27543464

17. Rudel LL, Kesaniemi YA. Low-density lipoprotein particle composition: what is the contribution to atherogenicity? Curr Opin Lipidol. 2000;11(3):227-8. doi: 10.1097/00041433200006000-00001 pmid: 10882336

18. Lada AT, Rudel LL. Associations of low density lipoprotein particle composition with atherogenicity. Curr Opin Lipidol. 2004;15(1):19-24. doi: 10.1097/00041433-20040200000005 pmid: 15166804

19. Miller GJ, Miller NE. Plasma-high-density-lipoprotein concentration and development of ischaemic heart-disease. Lancet. 1975;1(7897):16-9. doi: 10.1016/s01406736(75)92376-4 pmid: 46338
20. Izuhara M, Ono K, Shiomi H, Morimoto T, Furukawa $\mathrm{Y}$, Nakagawa $Y$, et al. High-density lipoprotein cholesterol levels and cardiovascular outcomes in Japanese patients after percutaneous coronary intervention: a report from the CREDO-Kyoto registry cohort-2. Atherosclerosis. 2015;242(2):632-8.

10.1016/j.atherosclerosis.2015.05.010 pmid: 26022139

21. Assmann G, Schulte H. Role of triglycerides in coronary artery disease: lessons from the Prospective Cardiovascular Munster Study. Am J Cardiol. 1992;70(19):10H-3H. doi: 10.1016/0002-9149(92)91084-h pmid: 1466311

22. Cullen P. Evidence that triglycerides are an independent coronary heart disease risk factor. Am J Cardiol. 2000;86(9):943-9. doi: 10.1016/s0002-9149(00)01127-9 pmid: 11053704

23. Hokanson JE, Austin MA. Plasma triglyceride level is a risk factor for cardiovascular disease independent of high-density lipoprotein cholesterol level: a meta-analysis of populationbased prospective studies. J Cardiovasc Risk. 1996;3(2):213-9. doi: $10.1177 / 174182679600300214$ pmid: 8836866

24. Hong MK, Romm PA, Reagan K, Green CE, Rackley CE. Usefulness of the total cholesterol to high-density lipoprotein cholesterol ratio in predicting angiographic coronary artery disease in women. Am J Cardiol. 1991;68(17):1646-50. doi: 10.1016/0002-9149(91)90323-d pmid: 1746467

25. Bampi AB, Rochitte CE, Favarato D, Lemos PA, da Luz PL. Comparison of non-invasive methods for the detection of coronary atherosclerosis. Clinics (Sao Paulo). 2009;64(7):675-82. doi: 10.1590/S180759322009000700012 pmid: 19606245

26. Flowers E, Molina C, Mathur A, Reaven GM. Use of plasma triglyceride/high-density lipoprotein cholesterol ratio to identify increased cardio-metabolic risk in young, healthy South Asians. Indian J Med Res. 2015;141(1):68-74. doi: 10.4103/0971-5916.154506 pmid: 25857497 